\title{
Exfoliation of graphite and expanded graphite by melt compounding to prepare reinforced, thermally and electrically conducting polyamide composites
}

Quang Binh $\mathrm{Ho}^{1}$, Osayuki Osazuwa ${ }^{1}$, Rebecca Modler ${ }^{1}$, Mark Daymond ${ }^{2}$, Mark T. Gallerneault ${ }^{2}$, Marianna Kontopoulou ${ }^{1 *}$

${ }^{1}$ Department of Chemical Engineering, Dupuis Hall, Queen's University, 19 Division Street, Kingston ON K7L 3N6, Canada

${ }^{2}$ Department of Mechanical and Materials Engineering, Queen's University 130 Stuart St, Kingston, ON K7L 2V9, Canada

\section{Abstract}

High performance composites based on a thermoplastic polyamide matrix containing well dispersed graphene nanoplatelets are prepared, by delaminating expanded graphite (EG) into its constituent graphene nanoplatelet (GNP) layers, by melt compounding. Results from scanning electron microscopy, transmission electron microscopy, and 3D tomography showed good dispersion of the GNP, while contact angle measurements reveal that the polyamide and graphene-based constituents have excellent interfacial interactions. Compared to flake graphite, exfoliation of EG into graphene nanoplatelets substantially improved the electrical, thermal and mechanical properties at low filler volume fractions: the electrical percolation threshold was attained at $1.9 \mathrm{vol} \%$, the thermal conductivity increased by $1300 \%$ at $8 \mathrm{vol} \%$, and the flexural modulus by $270 \%$ at $15 \mathrm{vol} \%$. Substantial improvements in the impact properties of the composites were imparted by adding a maleated elastomeric impact modifier, which was welldispersed within the PA matrix, resulting in excellent toughening performance. This research achieves composites with superior properties, using an industrially relevant, easy to implement melt compounding method.

Keywords: Expanded graphite; graphene nanoplatelets; composites; polyamide; melt compounding;

*Corresponding author: kontopm@ queensu.ca 


\section{INTRODUCTION}

The rising demand from the automotive, aerospace, electronics, and other value-added industries has driven the growth of advanced polymer composites. The capability of both enhancing and tuning engineering properties gives polymer composites a competitive advantage over neat polymers and other traditional materials such as metal alloys [1]. Reinforced polymers containing carbon fibres [2,3], layered silicates, glass fibres, and various particulate fillers offer improved mechanical properties and cost efficiency [4-7].

Carbon-based materials such as graphite, carbon nanotubes (CNTs), carbon black (CB) and graphene nanoplatelets (GNP) impart improved electrical and heat conductivity that are sought after in fields such as semiconductors and thermal management [8]. The resulting polymer composites offer an excellent combination of mechanical performance, electrical and thermal properties [9-12][13]. The final properties depend on many factors, such as filler concentration, filler-matrix interactions, and the size and shape of the filler material. For example, it is known that the electrical percolation thresholds and maximum conductivity of composites containing amorphous $\mathrm{CB}$ can be achieved at a concentration ranging from $1.6 \mathrm{vol} \%$ to $6.6 \mathrm{vol} \%$, respectively [12-16]. However, the addition of more than $10 \mathrm{wt} \% \mathrm{CB}$ may result in deterioration of the mechanical properties [15]. On the other hand, at the same filler concentration, composites filled with flake graphite exhibited higher electrical conductivity and flexural strength compared to those containing spherical graphite [17].

Flake graphite (FG), which has a platelet morphology, is commonly used to develop polymer composites with improved mechanical properties $[11,16]$. Delaminated FG particles may form a physical network when incorporated in a polymer matrix, thus increasing the composite's flexural rigidity. It has been reported that large graphite flakes fared better than small ones in 
increasing the flexural modulus of epoxy composites [18]. Limited delamination of graphene layers was observed in epoxy matrices, resulting in improved thermal stability of the composites; however, the amount of exfoliated graphite was low, and there was aggregation of filler materials due to poor interfacial interactions [11]. The resulting product was therefore a macrocomposite. The scope of this work is to develop an easy to implement, and industrially relevant method to produce polyamide-based nanocomposites in-situ, by exfoliating graphite into its constituent layers by melt compounding. Expanded graphite (EG) was selected, because it consists of graphene layers, which are loosely bonded with each other by weak van der Waals forces. They are therefore amenable to delamination into few and multi-layer graphene nanoplatelets, under the action of the shear forces that develop during melt compounding. This industrially relevant method therefore does not require prior exfoliation of graphite, or any of other chemical methods to create graphene separately. We compare the exfoliation potential of EG, with that of high purity FG. The improvement in the mechanical, electrical and thermal properties in all composites are evaluated on the basis of the microstructure of the dispersed filler.

\section{EXPERIMENTAL}

\subsection{Materials}

Natural flake graphite (FG) having a size range from $45 \mu \mathrm{m}$ to $220 \mu \mathrm{m}$, purity $>97 \%$, and expanded graphite (EG) with bulk density of $0.0245 \mathrm{~g} / \mathrm{mL}$, purity $>97 \%$, were supplied by Alcereco Inc., Canada. The specific surface areas were determined by the Brunauer-EmmettTeller (BET) method to be $4 \mathrm{~m}^{2} / \mathrm{g}$ for FG and $44 \mathrm{~m}^{2} / \mathrm{g}$ for EG.

A polyamide 6, 12 polymer (PA), Zytel 151, was obtained from DuPont Canada. A maleated ethylene-octene copolymer (EOC), Exxelor MDEX 95-2, was obtained from ExxonMobil Chemical, and used as an elastomeric impact modifier. All materials were used as-received. 


\subsection{Melt compounding and sample preparation}

PA was dried under vacuum at $60^{\circ} \mathrm{C}$ for 24 hours before compounding. A HaakePolylab torque rheometer connected to a Rheomix R600 batch mixer equipped with roller rotors was used to prepare the composites. Pre-determined amounts of PA were measured and added to the chamber, which was pre-heated to $220^{\circ} \mathrm{C}$ with the rotor speed set at $150 \mathrm{rpm}$. To ensure complete melting of PA, the mixing continued for one minute before the addition of fillers. The total compounding time was 6 minutes. For composites containing EOC, the impact modifier was dry mixed with PA before being added to the chamber. In this study, the weight content of EOC refers to its weight ratio with PA, e.g.100 g of PA/EOC 90/10 contains $90 \mathrm{~g}$ of PA and $10 \mathrm{~g}$ EOC. The weight percentage of FG or GNP is calculated on the total weight of the composite. The FG and EG fillers were added at amounts ranging from 4 vol\% and $15 \mathrm{vol} \%$ (corresponding to $9.0 \mathrm{wt} \%-28.5 \mathrm{wt} \%)$. The volume fraction, $\Phi$, of a filler in a composite is determined experimentally from the mass of each component $\left(m_{P A}, m_{\text {composite }}\right)$, and the densities of PA and of the composite $\left(d_{P A}, d_{\text {composite }}\right)$ :

$\Phi=\frac{V_{\text {filler }}}{V_{\text {composite }}} \times 100 \%=\left(1-\frac{m_{P A} / d_{P A}}{m_{\text {composite }} / d_{\text {composite }}}\right) \times 100 \%$

The densities of the PA and the composites were obtained by using a densimeter, according to the ASTM D792-00 standard.

Samples for characterization were prepared by compression molding using a Carver hydraulic press at a temperature of $230^{\circ} \mathrm{C}$ under an applied force of 2 tonnes, corresponding to a pressure range of 10-16 bar, followed by cooling to room temperature. They were left to stand at room conditions $\left(22^{\circ} \mathrm{C}, 40 \%\right.$ humidity) for 48 hours before further characterization. All testing was done at room temperature $\left(22-25^{\circ} \mathrm{C}\right)$, unless otherwise specified. 


\subsection{Characterizations of starting materials}

The bulk densities of FG and EG were determined according to the ASTM D7481-09 standard. The BET method was employed to obtain the specific surface area of FG and EG. Samples from $0.5 \mathrm{~g}$ to $1.0 \mathrm{~g}$ were degassed at $110^{\circ} \mathrm{C}$ for 24 hours and then subjected to a multipoint BET physisorption analysis (Autosorb-1 Quantachrome, USA) with nitrogen at relative vapour pressures in the range of $0.1-0.3$ at $77 \mathrm{~K}$.

The surface energies of PA, GNP, and FG were measured using the contact angle method. Water and methylene iodide were employed as testing liquids. In the preparation of thin films of GNP and FG, a dispersion of each material in N-methyl-2-pyrrolidone (NMP) was prepared at a loading of $4 \mathrm{mg} / \mathrm{mL}$ and sonicated for 1 hour. The excess solid was removed by centrifugation at $1,800 \mathrm{rpm}$ for 30 minutes. $0.25 \mathrm{~mL}$ of the supernatant was diluted with $9.75 \mathrm{~mL}$ of NMP before being sprayed on cleaned silicon oxide substrates. To ensure maximum coverage and to facilitate quick evaporation of NMP, the substrates were sprayed 15 times at a nozzle pressure of $3.0 \mathrm{bar}$ and were pre-heated on a hotplate at $220^{\circ} \mathrm{C}$ before each spray. The contact angles of sessile drops on the surface of the films were measured at $20^{\circ} \mathrm{C}$ with a goniometer (OCA 15EC, DataPhysics Instruments, Germany), equipped with a video camera and data analysis software. The dispersive and polar components of surface energy were calculated, and the resulting surface energies were extrapolated to $220^{\circ} \mathrm{C}$, assuming a linear relationship with a temperature coefficient of 0.058 $\mathrm{mJ} / \mathrm{m}^{2}$ [20]. Interfacial energies were estimated using the geometric mean equation:

$\gamma_{1 / 2}=\gamma_{1}+\gamma_{2}-2\left(\sqrt{\gamma_{1}^{d} \gamma_{2}^{d}}+\sqrt{\gamma_{1}^{p} \gamma_{2}^{p}}\right)$

where $\gamma_{1 / 2}$ is the interfacial energy, $\gamma_{1}$ and $\gamma_{2}$ are the total surface energy of matrix and filler respectively, superscripts $d$ and $p$ indicate the dispersive and polar components of the surface energy. 
X-ray photoelectron spectroscopy (XPS) was carried out on a Kratos Nova AXIS spectrometer equipped with an Al X-ray source. The samples were kept under high vacuum $\left(10^{-9} \mathrm{Torr}\right)$ overnight inside a preparation chamber before they were transferred into the analysis chamber (ultrahigh vacuum, $10^{-10}$ Torr) of the spectrometer. XPS data were collected using $\mathrm{AlK}_{\alpha}$ radiation at $1486.69 \mathrm{eV}(150 \mathrm{~W}, 15 \mathrm{kV})$, a charge neutralizer and a delay-line detector (DLD) consisting of three multi-channel plates. Survey spectra were recorded from -5 to $1200 \mathrm{eV}$ at a pass energy of $160 \mathrm{eV}$ (number of sweeps: 1) using an energy step size of $1 \mathrm{eV}$ and a dwell time of $200 \mathrm{~ms}$. High resolution spectra for $\mathrm{O} 1 \mathrm{~s}$ in the appropriate regions at a pass energy of $20 \mathrm{eV}$ (number of sweeps: O1s, 20) using a dwell time of $300 \mathrm{~s}$ and energy step sizes of $0.1 \mathrm{eV}$. The analyzed area on the specimens was about $300 \times 700 \mu \mathrm{m}^{2}$ (lens mode: FOV 1) at this position. The incident angle (X-ray source/sample) is $54.74^{\circ}$ and the take-off angle (sample/detector) is $90^{\circ}$. The spectra were measured using the Vision 2 software and processed using the CasaXPS software. The data were corrected for energy shifts due to charging of the sample under the influence of the X-rays, and the spectra were corrected for background using the Shirley algorithm.

\subsection{Imaging and X-Ray Diffraction}

Scanning electron microscopy (SEM) was carried out using a JEOL JMS-5800 microscope. Composite samples were fractured in liquid nitrogen, and the fracture surfaces were gold sputtered for 2 minutes before characterisation. Fracture surfaces of composites containing EOC were etched in xylene at $120^{\circ} \mathrm{C}$ for 1 hour to etch the dispersed phase before gold-sputtering. Transmission electron microscopy (TEM) was carried out using a FEI Tecnai 20 electron microscope with an operating voltage of $200 \mathrm{keV}$. Ultra-thin films of approximately $70 \mathrm{~nm}$ thick were prepared by cryo-sectioning using a Leica ultra-microtome. 
X-ray diffraction (XRD) patterns of fillers and polymer composites were obtained using a PanalyticalX'pert Pro Powder Diffractometer, with Cobalt K $\alpha 1,2$ radiation $\left(\lambda_{1}=1.7889 \AA\right.$, $\lambda_{2}=1.7928 \AA$ ) and an operating voltage of $45 \mathrm{kV}$. Composite samples were prepared by compression molding at 16 bar and $230^{\circ} \mathrm{C}$ for two minutes, followed by cutting into circular discs of $2 \mathrm{~mm}$ thick and $30 \mathrm{~mm}$ in diameter.

\subsection{3-D Tomography}

The distribution of fillers in the PA matrix was examined by X-ray micro-computed tomography (micro-CT) using an Xradia MicroXCT-400 High-Resolution 3D X-ray Imaging System. Scans for each sample were obtained using $4 \mathrm{X}$ magnification, $100 \mathrm{kV}$ voltage and $8.7 \mathrm{~W}$ over a $360^{\circ}$ rotation with 3,200 projections, resulting in 3,200 cross-sectional images with a resolution of 5.6 $\mu \mathrm{m}$. These images were reconstructed with Zeiss XM Reconstructor software and segmented using MATLAB to isolate the fillers from the matrix using different suitable thresholding values. Avizo Fire 8.1.1 software was used to render 3D volume tomography of the composites and calculate the filler volume fractions detected by micro-CT scans.

Thickness, length, and aspect ratio of FG were assessed from the 2D cross-sectional scans using the image analysis software program ImageJ (Version 1.52a) [21]. The dimensional analysis was performed at 50 slice intervals lengthwise. The software also calculated the average lateral length and the thickness of filler in SEM and TEM images.

\subsection{Characterization of mechanical, electrical, and thermal properties}

Flexural modulus tests (according to the ASTM D790 standard) and impact strength tests (according to the ASTM D256 standard) were carried out on a Universal Tester (Instron 3369) and an Izod Notched Impact Tester (SATEC System Inc.), respectively. Specimens with dimensions of $125 \mathrm{~mm} \times 12.5 \mathrm{~mm} \times 3 \mathrm{~mm}$ were prepared by compression molding the composite 
at 16 bar and $220^{\circ} \mathrm{C}$ for two minutes, followed by cooling to room temperature using a Dake Arbor press. For each compounding formulation, a minimum of 5 samples were tested. Samples for electrical resistivity measurements were prepared by compression molding composites at 12 bar and $220^{\circ} \mathrm{C}$ to produce $0.25 \mathrm{~mm}$ thin sheets. A Keithley 8009 electrometer was used to measure resistivity higher than $10^{7} \Omega \cdot \mathrm{cm}$ : a thin sheet of $130 \mathrm{~mm} \times 130 \mathrm{~mm}$ was placed in the chamber for an electrification time of one minute before the volume resistivity values were recorded. Sheets with resistivity of $10^{7} \Omega \cdot \mathrm{cm}$ or lower were measured using an Agilent 34401A multimeter. Both sides of sheets were gold-sputtered for 2 minutes and sheets were cut into squares of $10 \mathrm{~mm} \times 10 \mathrm{~mm}$. The fresh cut edge of samples ensured that no shortcircuit would happen when the resistance was measured across the sheet thickness. Five sheets per one formulation were measured. The volume resistivity was obtained by using the following formula:

$\rho=\frac{R(\Omega) \times A\left(m^{2}\right)}{l(m)}$

where $\rho(\Omega \cdot \mathrm{m})$ is the volume resistivity, $R(\Omega)$ is the resistance, $A\left(\mathrm{~m}^{2}\right)$ and $l(\mathrm{~m})$ are the area and thickness of the cut-out sample, respectively.

The electrical percolation threshold, defined as the concentration of filler above which the conductivity of the material increases exponentially, was estimated by fitting a power-law model below and above the threshold [22]:

$$
\begin{aligned}
& \sigma=\sigma_{\text {matrix }}\left(\frac{\varphi_{c}-\varphi}{\varphi_{c}}\right)^{-s}, \quad \varphi<\varphi_{c}, \\
& \sigma=m\left(\frac{\varphi-\varphi_{c}}{1-\varphi_{c}}\right)^{t} \approx m\left(\varphi-\varphi_{c}\right)^{t}, \quad \varphi>\varphi_{c}
\end{aligned}
$$


where $\varphi_{c}$ is the percolation threshold in volume fraction of filler, $\varphi$ is the volume fraction of filler, $\sigma$ is the conductivity of the sample, $\sigma_{\text {matrix }}$ is the initial matrix conductivity, $s$ and $t$ are the critical exponent factors below and above percolation respectively and $m$ is a constant.

The degree of crystallinity was measured by differential scanning calorimetry (DSC), using a TA Instruments DSC Q1000. The temperature was ramped up to $250^{\circ} \mathrm{C}$ at a rate of $10^{\circ} \mathrm{C} / \mathrm{min}\left(1^{\mathrm{st}}\right.$ heating curve $)$, held isothermally at $250^{\circ} \mathrm{C}$ for 5 minutes, cooled to $-20^{\circ} \mathrm{C}$ at $10^{\circ} \mathrm{C} / \mathrm{min}\left(1^{\text {st }}\right.$ cooling curve $)$, held isothermally at $-20^{\circ} \mathrm{C}$ for 5 minutes, and ramped to $250^{\circ} \mathrm{C}$ at $10^{\circ} \mathrm{C} / \mathrm{min}\left(2^{\text {nd }}\right.$ heating curve). The degree of crystallinity was calculated after correcting the heat of fusion for the amount of filler in the composite.

$\chi=\frac{\Delta H_{f}-\Delta H_{c}}{w \times \Delta H_{f, 100 \%}} \times 100 \%$

where $\Delta H_{f}$ is the heat of fusion obtained from the second heating curve, $\Delta H_{c}$ is the heat of cold crystallization, $\Delta H_{f, 100 \%}$ is the heat of fusion of a $100 \%$ crystalline polymer $\left(\Delta H_{f, 100 \%}=\right.$ $258 \mathrm{~J} / \mathrm{g}$ for polyamide 6,12 ), and $w$ is the weight fraction of polymer in the composites. The thermal diffusivity was measured using a Netzsch Laser Flash Analyser, according to the ASTM E1461 standard. Samples were prepared by compression molding at 10 bar and $220^{\circ} \mathrm{C}$ for one minute to produce $1.5 \mathrm{~mm}$ thin sheets, followed by cutting into circular discs of $25 \mathrm{~mm}$ in diameter. Five samples per formulation were tested at $22^{\circ} \mathrm{C}$. The thermal conductivity $k\left(\mathrm{~W} \mathrm{~m}^{-1}\right.$ $\mathrm{K}^{-1}$ ) was obtained from the formula:

$k=\alpha \cdot d \cdot C_{P}$

where $\alpha\left(\mathrm{m}^{2} / \mathrm{s}\right)$ is the thermal diffusivity, $d\left(\mathrm{~kg} / \mathrm{m}^{3}\right)$ is the density, and $C_{P}\left(\mathrm{Jkg}^{-1} \mathrm{~K}^{-1}\right)$ is the specific heat capacity of the composite. The density and the specific heat capacity were determined using the densimeter and differential scanning calorimeter, respectively. The data is included in the Supplementary Information. 


\section{RESULTS AND DISCUSSION}

\subsection{Filler characterization}

As shown in the SEM images (Fig. 1(c) and (d)), EG has an expanded structure, which can be contrasted to the tightly packed layered structure of FG (Fig. 1(a) and (b)). The degree of $\pi-\pi$ stacking in EG was lower than that of graphite, as evident in the characteristic $2 \theta=30.8^{\circ}$ peak intensity in the XRD patterns (Fig. S1 in Supplementary Information). The highly expanded structure of EG also manifests in the bulk densities of the loose powder, which is $0.025 \mathrm{~g} / \mathrm{cm}^{3}$ and lower than that of FG $\left(0.67 \mathrm{~g} / \mathrm{cm}^{3}\right)$. The lateral lengths of FG and EG, estimated from the SEM images, range from $50 \mu \mathrm{m}$ to $150 \mu \mathrm{m}$ and from $50 \mu \mathrm{m}$ to $330 \mu \mathrm{m}$, respectively. XPS results reveal that EG contained mostly carbon with surface purity of $>97 \%$ in atomic concentration, higher than that of FG (Table 1). Peaks at $529.6 \mathrm{eV}-535.1 \mathrm{eV}$ are attributed to the oxygen atoms in the $\mathrm{CO}_{2}$ molecules absorbed on the surface, and in other oxygen-containing groups such as carboxylic - $\mathrm{COOH}[23]$.

\subsection{Composite microstructure}

Melt compounding is expected to produce a wide range of microstructures within the polyamide matrix, ranging from nano- to micro-scale, depending on the degree of delamination. With an open structure and large interplanar space between the loosely bonded GNP constituent layers (Fig. 1), EG is expected to delaminate more effectively than FG. TEM images captured the delamination of FG and EG (Fig. 2). Thin GNP can be readily seen, as they were peeled off from thicker FG flakes (Fig. 2, $a-b$ ) and from EG (Fig. 2, $c$-d) under the action of the shearing forces. Overall, because of the weaker interlayer forces, there was a higher degree of exfoliation of EG, as seen from the denser distribution of GNP in the matrix (Fig. 2, $d$ ). A TEM image at larger magnification shows clearly the diffusion of the PA matrix into the interlayer spacing of EG, 
which would facilitate further delamination (Fig. 2,e). The filler particles are well encapsulated within the PA matrix, suggesting strong filler-matrix interactions. Image analysis suggested that the GNP in PA-EG have size distibutions from $0.07 \mu \mathrm{m}$ to $0.5 \mu \mathrm{m}$ in thickness, and from $10 \mu \mathrm{m}$ to $30 \mu \mathrm{m}$ in lateral length, resulting in aspect ratios ranging from 20 to 400 .

Fragmentation of EG during the compounding process is possible. Liscio et al. has shown different fragmentation mechanisms during ultrasonication of graphene oxide [24]. However, in this study, judging from the weak interlayer Van der Waals forces, we believe that delamination is likely to occur more readily than fragmentation, under the shear forces of melt compounding. The shear forces in the melt compounding process, as estimated from the applicable shear rates during compounding (between 50-100s ${ }^{-1}$ ) and typical melt viscosity of the composites (between 1000-10,000 Pa.s) are estimated to be in the order of 0.1-1 GPa [25]. A study by Chen et al., using AFM in conjunction with nonlinear mechanics modeling, found that the interlayer shear modulus between graphene layers is in the range of 0.36-0.49 GPa [26], which is in the same range with the shear forces and much lower than the theoretical modulus of elasticity of a graphene sheet (1 TPa) [27]. Therefore, the delamination mechanism is much more likely than fragmentation, considering that the shear stresses developed during compounding are of the order of magnitude of the former.

To capture the magnitude of the different types of structures, the TEM images are complemented by SEM images (Fig. 3). At $\Phi=8$ vol\%, the PA-EG composite was densely filled with GNP as shown on the fracture surface (Fig. 3, b), whereas PA-FG contained discrete thick flakes (Fig. 3, a). The good dispersion of fine GNP in PA-EG is attributed to the highly expanded structure of EG, leading to efficient delamination. 
Interesting insight into the shape and dispersion of the particles within the matrix can be provided through micro-CT scans. Fig. $4 a$ shows a cross-sectional micro-CT scan of a compression molded PA-FG at $\Phi=12.5$ vol $\%$. The FG fillers appear to be uniformly distributed throughout the matrix as individual particles. Multiple sequential 2D scans were stacked on one another to obtain the 3D rendering, which show the platelet-shaped FG particles (Fig. 4b). As observed on the 2D scan, the platelets in a PA-FG composite with $\Phi=12.5$ vol $\%$ are densely distributed and in close contact with one another, providing evidence of interconnected networks of FG fillers.

Image analysis on micro-CT scans along the sample length shows that $85 \%$ of all FG in the PAFG composite are from $40 \mu \mathrm{m}$ to $140 \mu \mathrm{m}$ in lateral length, while $15 \%$ of the flakes from $140 \mu \mathrm{m}$ to $220 \mu \mathrm{m}$. The analysis also showed that the thickness of dispersed FG ranges from $5 \mu \mathrm{m}$ to 50 $\mu \mathrm{m}$, with $80 \%$ of them is from $10 \mu \mathrm{m}$ to $30 \mu \mathrm{m}$. From these dimensions, the aspect ratios were calculated to be from 2 to 15 . Because of the resolution limitations, FG flakes that are smaller than $5 \mu \mathrm{m}$ would not register in the micro-CT imaging; however, a few flakes having dimensions less than this are present in the composite, as demonstrated by the TEM images (Fig. 2, $a-b$ ), thus verifying that there was some delamination of FG by melt compounding. This agrees with a study by Kim et al. which also found that graphite can be delaminated to flakes with thickness below $2 \mu \mathrm{m}$ in polyamide matrices [28].

Micro-CT scans and 3D renderings of the PA-EG composites could detect some EG aggregates having thickness in the range from $5 \mu \mathrm{m}$ to $25 \mu \mathrm{m}$, and length from $5 \mu \mathrm{m}$ to $80 \mu \mathrm{m}$. However, these large EG aggregates comprised a volume fraction of just $0.30 \mathrm{vol} \%$, which is much lower than the loading composition of 12.5 vol\%., therefore suggesting that most of the EG were finely delaminated into GNP, and therefore undetectable by the instrument, due to the detection limit of 
$5 \mu \mathrm{m}$. The thin GNP were revealed in the TEM images (Fig. 2, $c-d$ ) with measured thickness from $0.07 \mu \mathrm{m}$ to $0.5 \mu \mathrm{m}$. The extensive exfoliation of EG is also evident in the fracture surface being densely filled with GNP (Fig. 3b).

\subsection{Electrical conductivity}

The presence of interconnected FG and GNP particles increased the electrical conductivity by orders of magnitude, compared to the insulating PA matrix. Fitting of data to the equations of power-law model (equations $4 \mathrm{a}$ and $4 \mathrm{~b}$ ) revealed that electrical percolation thresholds were attained at $\Phi=9.0 \mathrm{vol} \%$ (17 wt $\%$ ) for PA-FG, and $1.9 \mathrm{vol} \%$ (4 wt $\%$ ) for PA-EG (Fig. 5). The maximum conductivity in the order of $10^{-2} \mathrm{~S} / \mathrm{m}$ was obtained at $\Phi=15$ vol\% for PA-FG, and at $\Phi=4$ vol $\%$ for PA-EG. The critical exponent $t$ of the best fitted Equation $4 \mathrm{~b}$ to the experimental results for PA-EG and PA-FG composites are 2.0 and 2.4 respectively. Exponent values around 2.0 were also reported by other studies with three-dimensional percolating systems [29-32].

It is well known that percolation is induced when the dispersed particles establish a conductive pathway. Such pathway is evident by the physical contact between FG flakes in the matrix, as shown in the micro-CT images of PA-FG (Fig.4). When the distance between neighbouring conductive particles reaches the tunnelling distance, which has been estimated to be in the order of few nm, electrons will be transferred across the distance, generating electrical conductivity [33-35]. Because PA does not have free electrons necessary for electrical conductivity, it is an electrical insulator. Therefore, once an electrical pathway is obtained at the percolation threshold, the conductivity increases exponentially.

The PA-EG composite has a significantly lower percolation threshold than PA-FG. This is attributed to the high surface area and aspect ratio of the well-dispersed GNPs, which promote a continuous, connected network of fillers. The formation of a continuous conductivity pathway is 
influenced by the separation distance between adjacent filler particles [33] and the matrix-filler interface [36]. Assuming same filler concentration and homogenous distribution of filler, fillers with smaller particle size or lateral size will increase the total matrix-filler interface and therefore do not promote interconnectivity. Therefore, large lateral size of GNP is favourable for electrical conductivity. Theoretical studies by Huang et al. and Martin et al. also found that in a polymer matrix containing carbon nanotubes (CNT), the electrical percolation threshold decreased with higher CNT aspect ratios [30,37].

Maximum conductivity in the range of $10^{-2} \mathrm{~S} / \mathrm{m}$ was also reported by other studies with polyamide containing graphite or expandable graphite $[13,38]$. However, the percolation thresholds reported for those composites were attained at $15 \mathrm{wt} \%$ filler content, which is higher than the threshold obtained in this study for PA-EG (1.9 vol\%, or $4 \mathrm{wt} \%)$. A very low percolation threshold at $1 \mathrm{wt} \%$ was obtained in composites containing conductive carbon black [12-16]; however the mechanical properties were compromised at loadings above $10 \mathrm{wt} \%$ [15].

\subsection{Thermal conductivity}

Graphene and graphite with crystalline structure is an excellent heat conductor with phonons being the main thermal carriers [39-41]. By contrast, PA is a poor heat conductor as all semicrystalline thermoplastics. Due to the presence of the amorphous regions, phonons diffuse slowly in polymers. Below the percolation threshold, heat is conducted mainly through the PA matrix, which has very low thermal conductivity. When the EG loading is higher than the percolation threshold, heat is transferred mainly through the thermal conduction pathways [42]. Therefore, upon adding EG to 4 vol\% to the matrices, the thermal conductivity significantly increased from $0.18 \mathrm{~W} \mathrm{~m}^{-1} \mathrm{~K}^{-1}$ of neat PA to $2.5 \mathrm{~W} \mathrm{~m}^{-1} \mathrm{~K}^{-1}$ of PA-EG at 8 vol\% (Fig.6). The thermal 
conductivities obtained in this work are in the same order of magnitude as those achieved in polyamide-graphene composites by other studies $[43,44]$.

The increase in thermal conductivity did not follow the exponential percolation as observed in the electrical conductivity. This is because PA is an electrical insulator but still capable of conducting heat. Fig. 6 also shows that $k$ did not change upon further increase of the GNP content from 8 vol\% to 15 vol\%. This suggests that the thermal conductivity in this composition range was hindered by the filler-matrix interface, which increased significantly with higher loadings of EG. Studies have reported that the graphene-polymer interface has high thermal resistance because it scatters phonons $[42,45]$.

It should be mentioned that at the same filler loading, GNP imparts higher thermal conductivity than FG. At 12.0 vol\%, the thermal conductivity of PA-FG is $1.2 \mathrm{~W} \mathrm{~m}^{-1} \mathrm{~K}^{-1}$, while that of PA-EG is double, at $2.5 \mathrm{~W} \mathrm{~m}^{-1} \mathrm{~K}^{-1}$. This confirms that there is less extent of connectivity among individual graphite flakes in PA-FG than among GNP in PA-EG, which is necessary for high thermal conductivity.

\subsection{Interfacial and mechanical properties}

The SEM and TEM images (Fig. 2 and Fig. 3) show evidence of good incorporation of GNP in the PA matrix. This suggests that there are good interfacial interactions. For further evaluation of interfacial properties, the contact angle method was employed to determine the constituent and total surface energies of the filler and the matrix. The total surface energies of PA and GNP are $43.4 \mathrm{~mJ} / \mathrm{m}^{2}$ and $42.9 \mathrm{~mJ} / \mathrm{m}^{2}$ respectively. Our results agree with those obtained by Kozbial et al. and Wang et al. using the same method, in which the surface energy of chemical vapour deposited graphene and reduced graphene are $46.7 \mathrm{~mJ} / \mathrm{m}^{2}$ and $45.6 \mathrm{~mJ} / \mathrm{m}^{2}$ respectively [46,47]. 
On the other hand, FG has higher surface energy than GNP; this may be due to the presence of oxygen-containing groups on FG surface, as evident in the XPS results in Table 1.

The similar surface energies of PA and GNP minimize the interfacial energy, enhancing the wetting of the matrix on the fillers and improving the dispersion. As fillers form a network of physical cross-links between the polyamide chains, a good dispersion provides better enhancement to the mechanical properties of the composite. Indeed, Fig.7 shows the improvements in the flexural moduli of PA-FG and PA-EG composites, with respect to the neat matrix.

In comparison with PA-FG, PA-EG composites had higher flexural moduli at the same filler content, due to the presence of delaminated platelets with higher aspect ratios. It should be noted that, in addition to the reinforcement effect of the filler, modulus enhancements may also be attributed to changes in the crystallinity. However, in the present case, evaluation of the degree of crystallinity by DSC showed that the crystallinity of neat PA and all composites are approximately $17 \%$, suggesting the presence of GNP did not alter the degree of crystallinity of the polymer. Therefore, the increase in flexural modulus is only attributed to the reinforcement effect of the fillers.

Insights on the effects of the filler aspect ratio on the flexural modulus can be obtained by using the Halpin-Tsai model (Equations 8(a)-(c)).

$$
\begin{aligned}
& E=E_{m} \frac{\left(1+\eta \cdot \varepsilon \cdot \Phi_{f}\right)}{\left(1-\eta \cdot \Phi_{f}\right)} \\
& \eta=\left(\frac{E_{f}}{E_{m}}-1\right) /\left(\frac{E_{f}}{E_{m}}+\varepsilon\right) \\
& \varepsilon=\frac{2}{3 a}
\end{aligned}
$$


where $E_{m}$ is the flexural modulus of the neat PA matrix, $E_{f}$ is the modulus of filler, the factor $\varepsilon$ represents the influence of the geometry of the reinforcing filler on the composite's properties, $\Phi_{f}$ is the filler's volume fraction, and $a$ is the aspect ratio of the filler.

The H-T model assumes good interfacial interactions, leading to a homogenous dispersion of discrete particles in this matrix-filler system [48,49]. As shown in Table 2, PA and the GNP and FG fillers have indeed similar surface energies, and therefore for the purposes of our analysis, we consider that this assumption is valid.

In applying the H-T model (equations 8(a) to (c)) to our experimental data, we used the modulus and the aspect ratio of the filler as fitting parameters. To obtain an initial estimate of the value of the filler's modulus we considered that graphite has a layered structure; as a result, the applied stress will likely cause the interlayer van der Waals bonds to fail before breaking the in-plane covalent carbon-carbon bonds. The modulus of the exfoliated individual layers was used as a first estimate of the filler's modulus; this value was reported to be below $40 \mathrm{GPa}$ [50-52]. Fig.7 shows good fits of the flexural data of PA-EG composites when using a filler modulus between $25 \mathrm{GPa}$ and $35 \mathrm{GPa}$, and aspect ratios of 60 and 27, respectively; these values are within the aspect ratio range measured by the image analysis on SEM and TEM images. Using the same filler flexural modulus values for FG for comparison, results in a fitted FG filler aspect ratio of about 5 .

Based on these results it becomes clear that there is an inverse correlation between the filler aspect ratio and its effective flexural modulus: at a given filler content, fillers with higher aspect ratio are more effective in providing the flexural reinforcement to the composites. When a highmodulus filler is added to a lower-modulus polymer matric, the load transfers from the matrix to 
the filler. The higher the filler aspect ratio, the longer the length that carries the maximum load, and the higher the composite modulus [53] [54,55].

The dependence of composite flexural modulus on GNP aspect ratios can be shown better in Figure 8, which summarizes different modulus-aspect ratio combinations that produced good fits of the H-T model to the PA-EG experimental results. Fig. 8 reveals that, when GNP aspect ratios are below 50, the modulus of the filler must be very high to accomplish the same reinforcement effect. However, aspect ratios beyond 50 result in effective reinforcement, without the need for high filler modulus. A study by Li et al. also found a similar trend in the flexural modulus of carbon nanotubes, which increased rapidly with aspect ratio when the aspect ratio was below 10 , but remained constant at aspect ratios higher than that [55].

Contrary to what is expected with most filled systems, the presence of highly exfoliated GNP did not significantly alter the flexural strength and impact strength of the composite, as shown in Figures 9a and 9b; this is attributed to the excellent interfacial interactions, which result in efficient physical interlocking between the GNP particles and PA molecules. The small reduction in the impact strength is due to the modification of the polymer matrix's morphology from a cohesive, continuous single phase of polymer to a filled network with phase boundaries. To further improve the toughness, an impact modifier, EOC, was added to the PA-EG composites. Such impact modifiers are considered very effective in enhancing the impact strength of the composites [56,57]. Close examination of the morphology of a composite (with PA:EOC ratio of 80:20 and GNPs of 8 vol\%) shows that the EOC was finely dispersed in PA matrices in the form of dispersed particles with size of $1 \mu \mathrm{m}$ (Fig. 11). The dispersed EOC can absorb and dissipate impact forces, preventing breakage and failure. The effect of EOC concentration was evaluated by adding it to PA-EG composites $(\Phi=15$ vol\%) at different 
PA/EOC weight ratios: from 90/10 to 60/40. Fig. 10 shows that with increased EOC content, the impact strength of PA-EG was enhanced significantly, whereas the decrease in the flexural modulus is attributed to the anticipated softening of the composite in the presence of the elastomeric phase.

\section{CONCLUSIONS}

Expanded graphite can be effectively delaminated under the action of shear forces encountered during melt compounding. The resulting GNP were dispersed uniformly in a PA matrix. The good interactions between the high aspect ratio GNPs and PA matrices improved dramatically the flexural modulus by $270 \%$, imparted high electrical and thermal conductivity with very low electrical percolation threshold of $1.9 \mathrm{vol} \%$. By adding a maleated impact modifier elastomer, it is further possible to obtain composites with substantially improved impact strength. The tuneable properties of the composites by incorporating GNPs and EOC at various contents allow for the formulation and design of PA composites for different industrial applications.

\section{Acknowledgements}

We would like to thank Mitacs and Grafoid Inc. for providing funding, Grafoid Inc. for providing graphite and expanded graphite, and DuPont Canada for supplying the polymers.

\section{References}

[1] M. Todor, I. Kiss, Systematic approach on materials selection in the automotive industry for making vehicles lighter, safer and more fuel-efficient, Appl. Eng. Lett. 1 (2016) 91-97.

[2] K. Kong, O. Kwon, H.W. Park, Enhanced mechanical and thermal properties of hybrid $\mathrm{SnO}_{2}$ e-woven carbon fiber composites using the facile controlled growth method, Compos. Sci. Technol. 133 (2016) 60-69. doi:10.1016/j.compscitech.2016.07.017.

[3] B. Jiang, T. Zhang, L. Zhao, Y. Huang, Interfacially reinforced carbon fi ber composites by grafting modi fi ed methylsilicone resin, Compos. Sci. Technol. 140 (2017) 39-45. doi:10.1016/j.compscitech.2016.12.022.

[4] Z. Zhang, Q. Shi, J. Peng, J. Song, Q. Chen, Partial delamination of the organomontmorillonite with surfactant containing hydroxyl groups in maleated poly ( propylene carbonate ), Polymer (Guildf). 47 (2006) 8548-8555. doi:10.1016/j.polymer.2006.09.041. 
[5] M. Alexandre, P. Dubois, Polymer-layered silicate nanocomposites : preparation, properties and uses of a new class of materials, Mater. Sci. Eng. 28 (2000) 1-63.

[6] P. Kushwaha, R. Kumar, The Studies on Performance of Epoxy and Polyester-based Composites Reinforced with Bamboo and Glass Fibers, J. Reinf. Plast. Compos. 29 (2010) 1952-1962. doi:10.1177/0731684409342006.

[7] F. Leroux, J. Besse, Polymer Interleaved Layered Double Hydroxide : A New Emerging Class of Nanocomposites, Chem. Mater. 13 (2001) 3507-3515. doi:10.1021/cm0110268.

[8] T. Kuilla, S. Bhadra, D. Yao, N.H. Kim, S. Bose, J.H. Lee, Recent advances in graphene based polymer composites, Prog. Polym. Sci. 35 (2010) 1350-1375. doi:10.1016/j.progpolymsci.2010.07.005.

[9] C. Zang, X. Zhu, Q. Jiao, Enhanced mechanical and electrical properties of nylon-6 composite by using carbon fiber / graphene multiscale structure as additive, J. Appl. Polym. Sci. 132 (2015) 41968. doi:10.1002/app.41968.

[10] J.A. King, D.R. Klimek, I. Miskioglu, G.M. Odegard, Mechanical properties of graphene nanoplatelet/epoxy composites, J. Compos. Mater. 49 (2015) 659-668. doi: $10.1177 / 0021998314522674$.

[11] B. Debelak, K. Lafdi, Use of exfoliated graphite filler to enhance polymer physical properties, Carbon 45 (2007) 1727-1734. doi:10.1016/j.carbon.2007.05.010.

[12] D. Hofmann, M. Keinath, R. Thomann, M. Rolf, Thermoplastic Carbon / Polyamide 12 Composites Containing Functionalized Graphene, Expanded Graphite, and Carbon Nanofillers a, Macromol. Mater. Eng. (2014) 1329-1342. doi:10.1002/mame.201400066.

[13] J.A. Heiser, J.A. King, J.P. Konell, L.L. Sutter, Electrical Conductivity of Carbon Filled Nylon 6, 6, Adv. Polym. Technol. 23 (2003) 135-146. doi:10.1002/adv.20004.

[14] A. Dorigato, M. Brugnara, A. Pegoretti, Novel polyamide 12 based nanocomposites for industrial applications, J. Polym. Res. 24 (2017) 1-13. doi:10.1007/s10965-017-1257-9.

[15] O. Koysuren, S. Yesil, G. Bayram, Effect of composite preparation techniques on electrical and mechanical properties and morphology of nylon 6 based conductive polymer composites, J. Appl. Polym. Sci. 102 (2006) 2520-2526. doi:10.1002/app.24654.

[16] H. Fukushima, L.T. Drzal, E.L. Mi, Nylon - Exfoliated Graphite Nanoplatelet ( xGnP ) Nanocomposites with Enhanced Mechanical, Electrical and Thermal Properties, NSTINanotech. 1 (2006) 282-285.

[17] S.I. Heo, J.C. Yun, K.S. Oh, K.S. Han, Influence of particle size and shape on electrical and mechanical properties of graphite reinforced conductive polymer composites for the bipolar plate of PEM fuel cells, Adv. Compos. Mater. 15 (2006) 115-126.

[18] S. Chatterjee, F. Nafezarefi, N.H. Tai, L. Schlagenhauf, F.A. Nu, Size and synergy effects of nanofiller hybrids including graphene nanoplatelets and carbon nanotubes in mechanical properties of epoxy composites, Carbon 50 (2012) 5380-5386.

[19] F.M. Uhl, Q. Yao, H. Nakajima, E. Manias, C.A. Wilkie, Expandable 
graphite/polyamide-6 nanocomposites, Polym. Degrad. Stab. 89 (2005) 70-84.

[20] S. Wu, Polymer Interface and Adhesion, 1982.

[21] W.S. Rasband, ImageJ, (2018). https://imagej.nih.gov/ij/.

[22] K. Petrie, M. Kontopoulou, A. Docoslis, Noncovalent Compatibilization of Polypropylene/ MWCNT Composites Using an Amino-Pyridine Grafted Polypropylene Matrix Kyle, Polym. Compos. (2015) 787-798. doi:10.1002/pc.

[23] J. Zhao, L. Liu, F. Li, Structural Characterization, in: Graphene Oxide Phys. Appl., 2015: pp. 15-30. doi:10.1007/978-3-662-44829-8.

[24] A. Liscio, K. Kouroupis-agalou, X.D. Betriu, A. Kovtun, Evolution of the size and shape of 2D nanosheets during ultrasonic fragmentation Evolution of the size and shape of 2D nanosheets during ultrasonic fragmentation, 2D Mater. 4 (2017) 025017.

[25] DuPont Engineering Polymers - Molding Manual for Minlon and Zytel resins, n.d.

[26] X. Chen, C. Yi, C. Ke, Bending stiffness and interlayer shear modulus of few-layer graphene, Appl. Phys. Lett. 106 (2015) 101907. doi:10.1063/1.4915075.

[27] D. Cai, M. Song, Recent advance in functionalized graphene/polymer nanocomposites, J. Mater. Chem. 20 (2010) 7906. doi:10.1039/c0jm00530d.

[28] S.R. Kim, M. Poostforush, J.H. Kim, S.G. Lee, Thermal diffusivity of in-situ exfoliated graphite intercalated compound/polyamide and graphite/polyamide composites, Express Polym. Lett. 6 (2012) 476-484. doi:10.3144/expresspolymlett.2012.50.

[29] A. Nogales, G. Broza, Z. Roslaniec, K. Schulte, I. Šics, B.S. Hsiao, A. Sanz, M.C. García-Gutiérrez, D.R. Rueda, C. Domingo, T.A. Ezquerra, Low Percolation Threshold in Nanocomposites Based on Oxidized Single Wall Carbon Nanotubes and Poly(butylene terephthalate), Macromolecules. 37 (2004) 7669-7672. doi:10.1021/ma049440r.

[30] C.A. Martin, J.K.W. Sandler, M.S.P. Shaffer, M.K. Schwarz, W. Bauhofer, K. Schulte, A.H. Windle, Formation of percolating networks in multi-wall carbon-nanotube-epoxy composites, Compos. Sci. Technol. 64 (2004) 2309-2316.

[31] J.K.W. Sandler, J.E. Kirk, I.A. Kinloch, M.S.P. Shaffer, A.H. Windle, Ultra-low electrical percolation threshold in carbon-nanotube-epoxy composites, Polymer 44 (2003) 58935899. doi:10.1016/S0032-3861(03)00539-1.

[32] O. Regev, P.N.B. ElKati, J. Loos, C.E. Koning, Preparation of conductive nanotubepolymer composites using latex technology, Adv. Mater. 16 (2004) 248-251.

[33] C. Gau, C.Y. Kuo, H.S. Ko, Electron tunneling in carbon nanotube composites, Nanotechnology. 20 (2009). doi:10.1088/0957-4484/20/39/395705.

[34] Y. Zare, K.Y. Rhee, A simple methodology to predict the tunneling conductivity of polymer/CNT nanocomposites by the roles of tunneling distance, interphase and CNT waviness, RSC Adv. 7 (2017) 34912-34921. doi:10.1039/c7ra04034b.

[35] A.B. Oskouyi, U. Sundararaj, P. Mertiny, Tunneling conductivity and piezoresistivity of 
composites containing randomly dispersed conductive nano-platelets, Materials (Basel). 7 (2014) 2501-2521. doi:10.3390/ma7042501.

[36] A. Lazarenko, L. Vovchenko, Y. Prylutskyy, L. Matzuy, U. Ritter, P. Scharff, Mechanism of thermal and electrical conductivity in polymer-nanocarbon composites, (2009).

[37] Y. Huang, W. Wang, X. Zeng, X. Guo, Y. Zhang, P. Liu, Effects of the filler size on the electrical percolation threshold of carbon black - carbon nanotube - polymer composites, 46517 (2018) 1-8. doi:10.1002/app.46517.

[38] S. Zhou, L. Yu, X. Song, J. Chang, H. Zou, M. Liang, Preparation of Highly Thermally Conducting Polyamide 6 / Graphite Composites via Low-Temperature In Situ Expansion, J. Appl. Polym. Sci. 6 (2014) 1-10. doi:10.1002/app.39596.

[39] S.K. Jaćimovski, M. Bukurov, J.P. Šetrajčić, D.I. Raković, Phonon thermal conductivity of graphene, Superlattices Microstruct. 88 (2015) 330-337. doi:10.1016/j.spmi.2015.09.027.

[40] A.A. Balandin, Thermal properties of graphene and nanostructured carbon materials, Nat. Mater. 10 (2011) 569-581. doi:10.1038/nmat3064.

[41] R. Narula, N. Bonini, N. Marzari, S. Reich, Dominant phonon wave vectors and straininduced splitting of the 2D Raman mode of graphene, Phys. Rev. B. 85 (2012) 115451.

[42] A. Li, C. Zhang, Y.F. Zhang, Thermal conductivity of graphene-polymer composites: Mechanisms, properties, and applications, Polymers (Basel). 9 (2017) 1-17.

[43] S.M. Hamidinejad, R.K.M. Chu, B. Zhao, C.B. Park, T. Filleter, Enhanced Thermal Conductivity of Graphene Nanoplatelet-Polymer Nanocomposites Fabricated via Supercritical Fluid-Assisted in Situ Exfoliation, ACS Appl. Mater. Interfaces. 10 (2018) 1225-1236.

[44] B.F. Xu, Z.D. Lin, C.M. Du, H.B. Lin, K.Y. Liang, W.P. Qiu, G.L. Yang, Mechanical properties, morphology and thermal conductivity of polyamide composites filled with graphene nanoplatelets, $\mathrm{Al}_{2} \mathrm{O}_{3}$ and graphite, Mater. Res. Innov. 19 (2015) S1-388-S1-391.

[45] Y. Liu, J. Huang, B. Yang, B.G. Sumpter, R. Qiao, Duality of the interfacial thermal conductance in graphene-based nanocomposites, Carbon 75 (2014) 169-177.

[46] A. Kozbial, Z. Li, C. Conaway, R. McGinley, S. Dhingra, V. Vahdat, F. Zhou, B. Durso, H. Liu, L. Li, Study on the surface energy of graphene by contact angle measurements, Langmuir. 30 (2014) 8598-8606. doi:10.1021/la5018328.

[47] S. Wang, Y. Zhang, N. Abidi, L. Cabrales, Wettability and surface free energy of graphene films, Langmuir. 25 (2009) 11078-11081. doi:10.1021/la901402f.

[48] Y. Zare, Development of Halpin-Tsai model for polymer nanocomposites assuming interphase properties and nanofiller size, Polym. Test. 51 (2016) 69-73.

[49] M. Abdel Ghafaar, A.A. Mazen, N.A. El-Mahallawy, Application of the Rule of Mixtures and Halpin-Tsai Equations to Woven Fabric Reinforced Epoxy Composites, J. Eng. Sci. Assiut Univ. 34 (2006) 227-236. http://www.aun.edu.eg/journal_files/186_J_6824.pdf.

[50] B. Hajgató, S. Güryel, Y. Dauphin, J.M. Blairon, H.E. Miltner, G. Van Lier, F. De Proft, P. Geerlings, Out-of-plane shear and out-of plane Young's modulus of double-layer graphene, 
Chem. Phys. Lett. 564 (2013) 37-40. doi:10.1016/j.cplett.2013.02.018.

[51] C. Feng, Y. Wang, S. Kitipornchai, J. Yang, Effects of reorientation of graphene platelets (GPLs) on Young's modulus of polymer nanocomposites under uni-axial stretching, Polymers (Basel). 9 (2017).

[52] J. Cho, J.J. Luo, I.M. Daniel, Mechanical characterization of graphite/epoxy nanocomposites by multi-scale analysis, Compos. Sci. Technol. 67 (2007) 2399-2407.

[53] P. Ajayan, L.S. Schadler, P. Braun, Modulus and the Load-Carrying Capability of Nanofillers, in: Nanocomposite Sci. Technol., John Wiley \& Sons, 2006: p. 122.

[54] A. Weerasinghe, C. Lu, D. Maroudas, A. Ramasubramaniam, Multiscale Shear-Lag Analysis of Sti ff ness Enhancement in Polymer - Graphene Nanocomposites, ACS Appl. Mater. Interfaces. 9 (2017) 23092-23098. doi:10.1021/acsami.7b03159.

[55] X.L. Gao, K. Li, A shear-lag model for carbon nanotube-reinforced polymer composites, Int. J. Solids Struct. 42 (2005) 1649-1667. doi:10.1016/j.ijsolstr.2004.08.020.

[56] Y. Liu, M. Kontopoulou, Effect of Filler Partitioning on the Mechanical Properties of TPO/Nanosilica Composites, J. Vinyl Addit. Technol. 3 (2007) 147-150.

[57] S.H. Lee, M. Bailly, M. Kontopoulou, Morphology and properties of poly(propylene)/ethylene-octene copolymer blends containing nanosilica, Macromol. Mater. Eng. 297 (2012) 95-103. doi:10.1002/mame.201100147. 


\section{Figures and Tables}
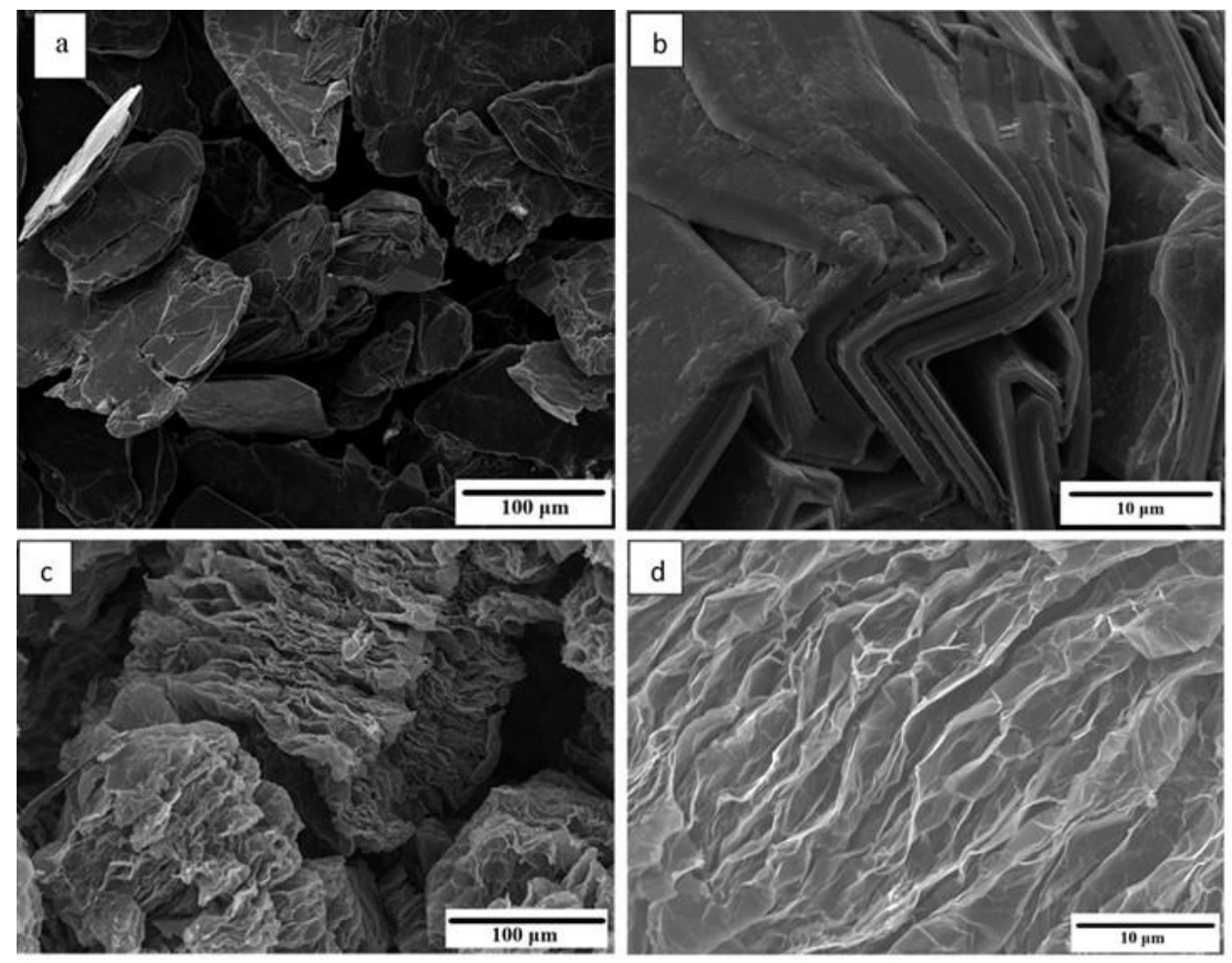

Figure 1: SEM images of starting materials. (a) Flake graphite FG, (b) Close-up edge-on view of flake graphite, (c) Highly expanded graphite EG, (d) Close-up edge-on view of EG 


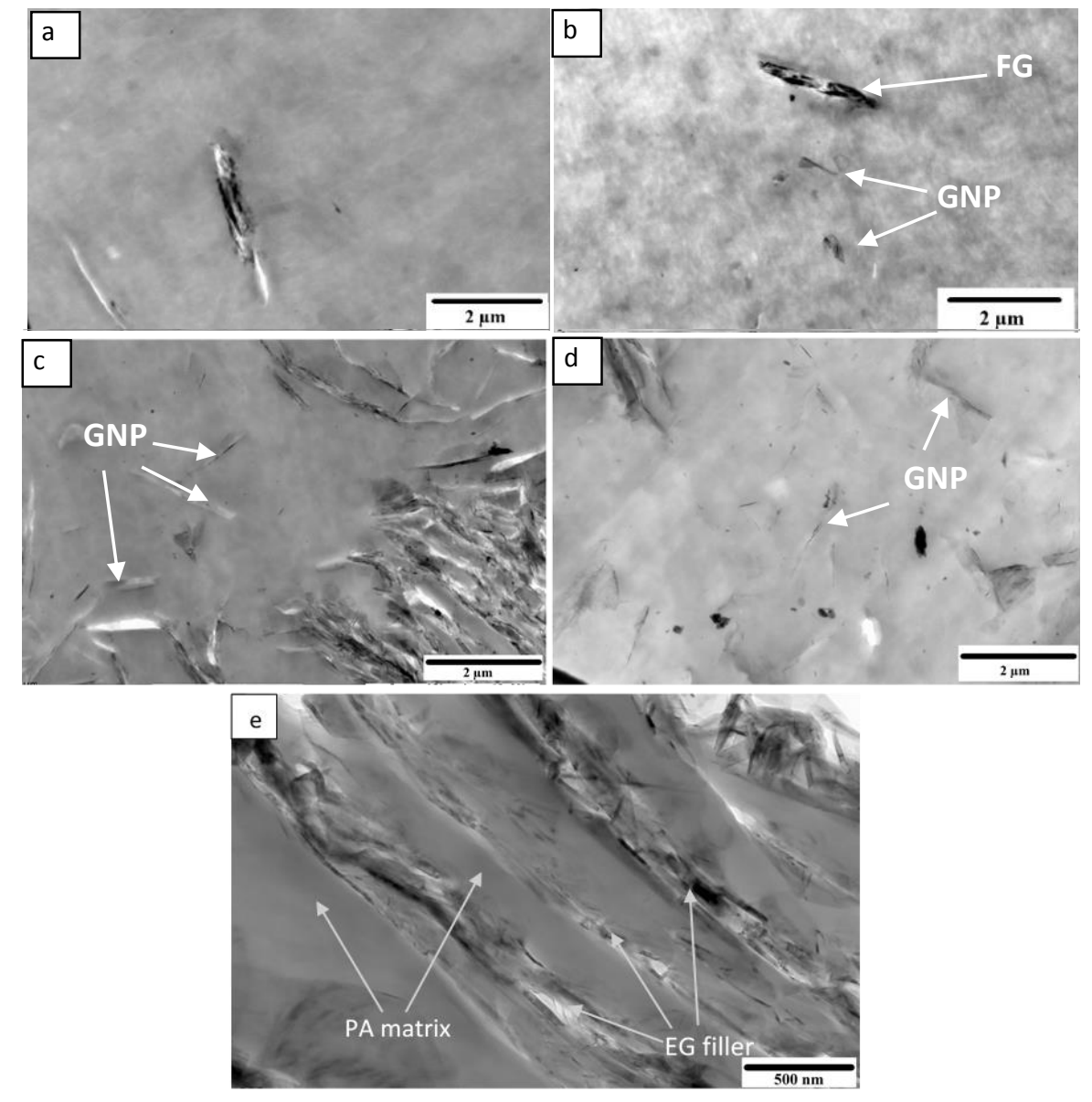

Figure 2: TEM images of PA-FG and PA-EG composites. (a) A FG flake in PA matrix (b) Thinner flakes 'peeled off' from a thick FG flake (c) Mixture of EG and delaminated flakes in PA matrix. (d) Delaminated flakes are embedded in the polyamide matrix. (e) EG structure "swollen" by the polymer. 


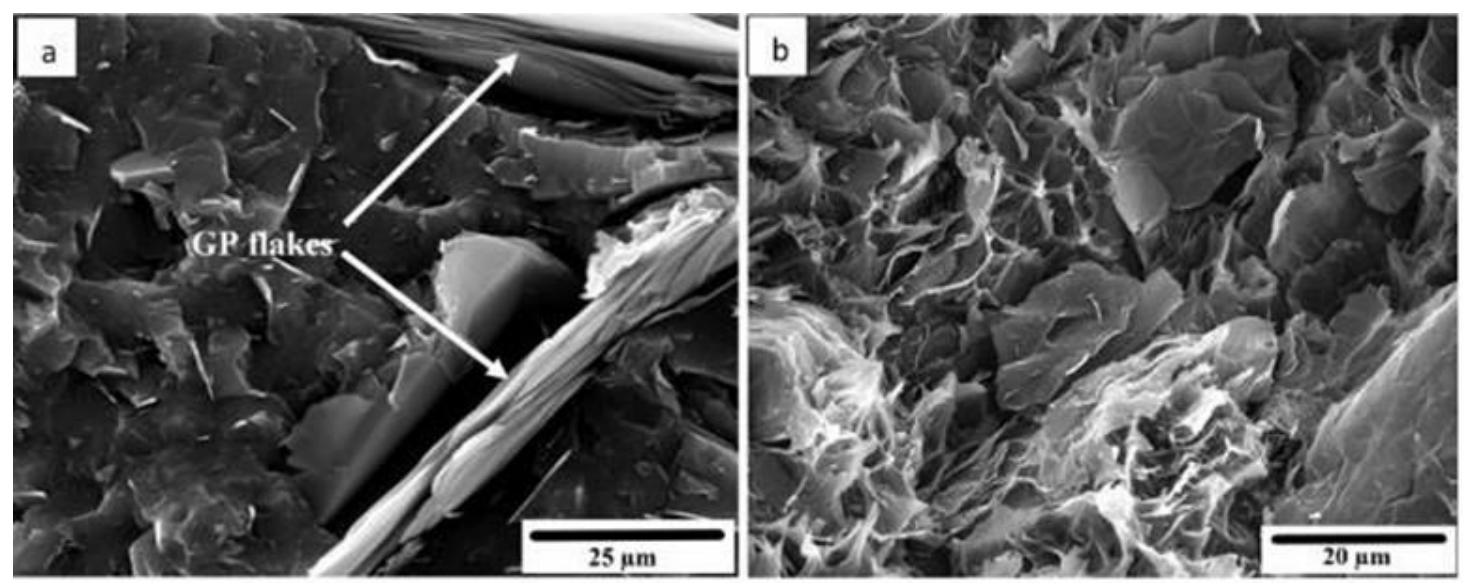

Figure 3: SEM images of cryo-fracture surface of (a) PA-FG and (b) PA-EG composites at $\Phi=8$ vol $\%$.
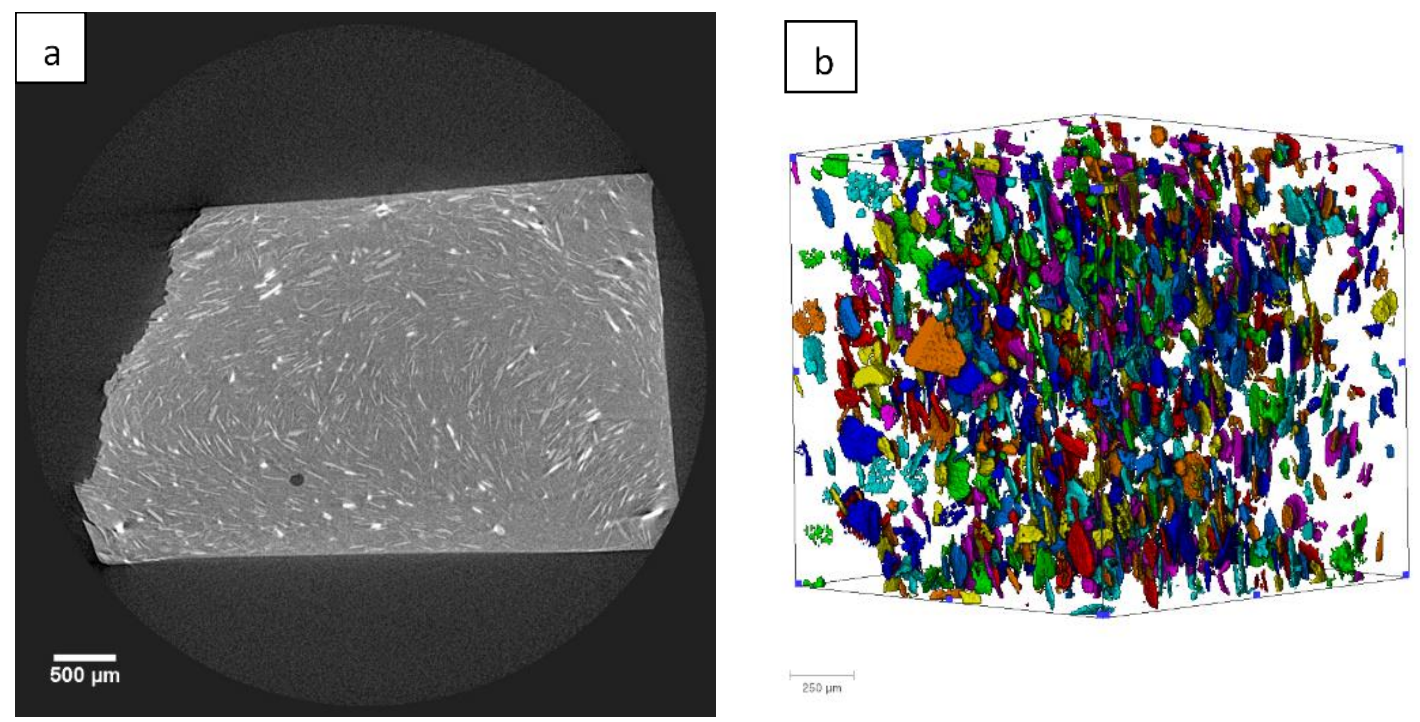

Figure 4: Micro-CT scans of PA-FG composite containing 12.5 vol\% of FG: (a) A crosssectional 2D scan. (b) 3D rendering of a subsection of the sample. 


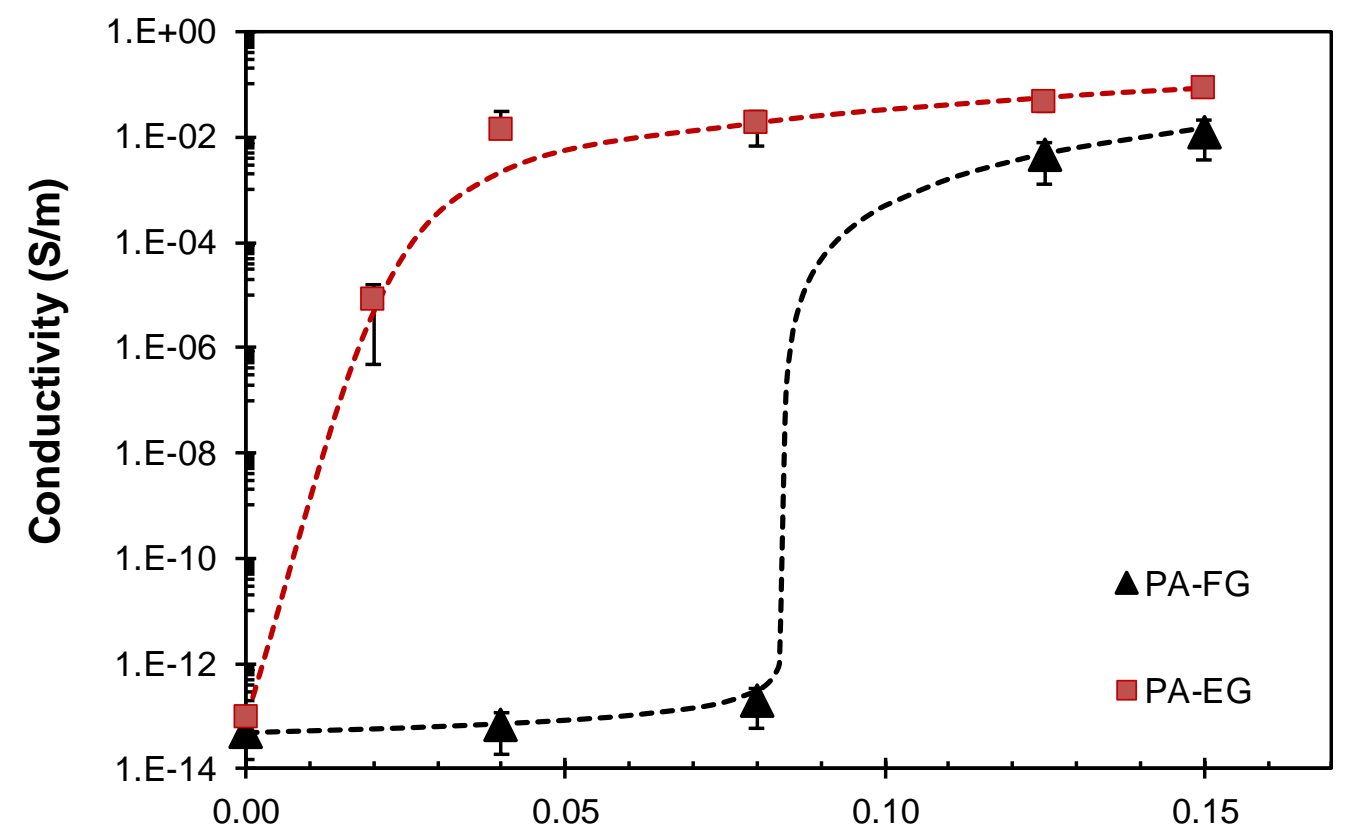

Filler volume fraction

Figure 5: Mean values of electrical conductivity of PA-FG and PA-EG as a function of filler volume fractions. The dotted lines were obtained by fitting the conductivity results to Equations $4 \mathrm{a}$ and $4 \mathrm{~b}$. 


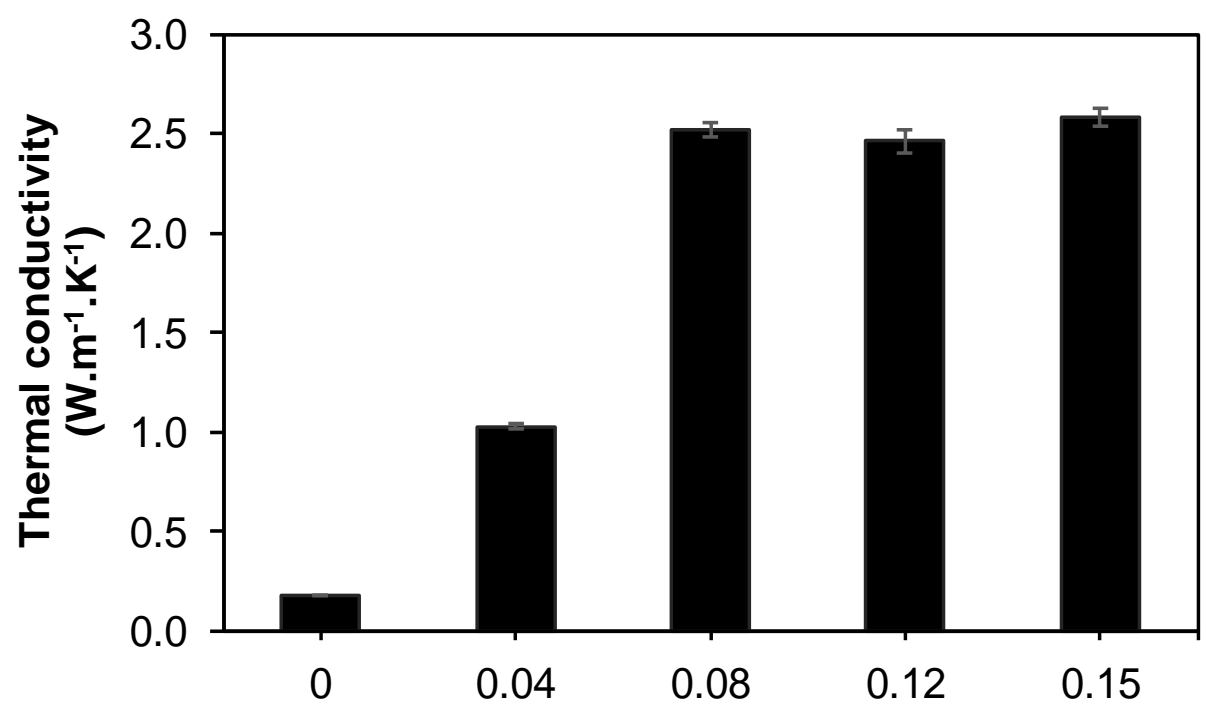

Filler volume fraction

Figure 6: Thermal conductivity of PA-EG at different filler volume fractions. Error bars show \pm 1 standard deviation.

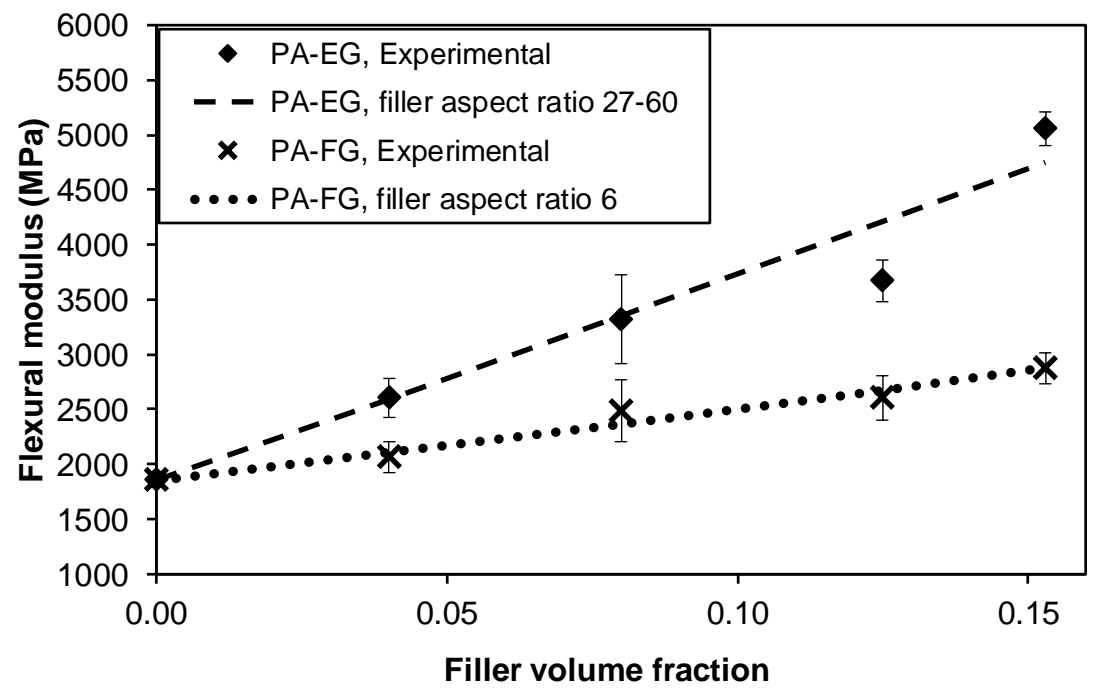

Figure 7: Flexural moduli of composites: fitting Halpin-Tsai's model using the GNP moduli and aspect ratios as adjusted parameters. Error bars show \pm 1 standard deviation. 


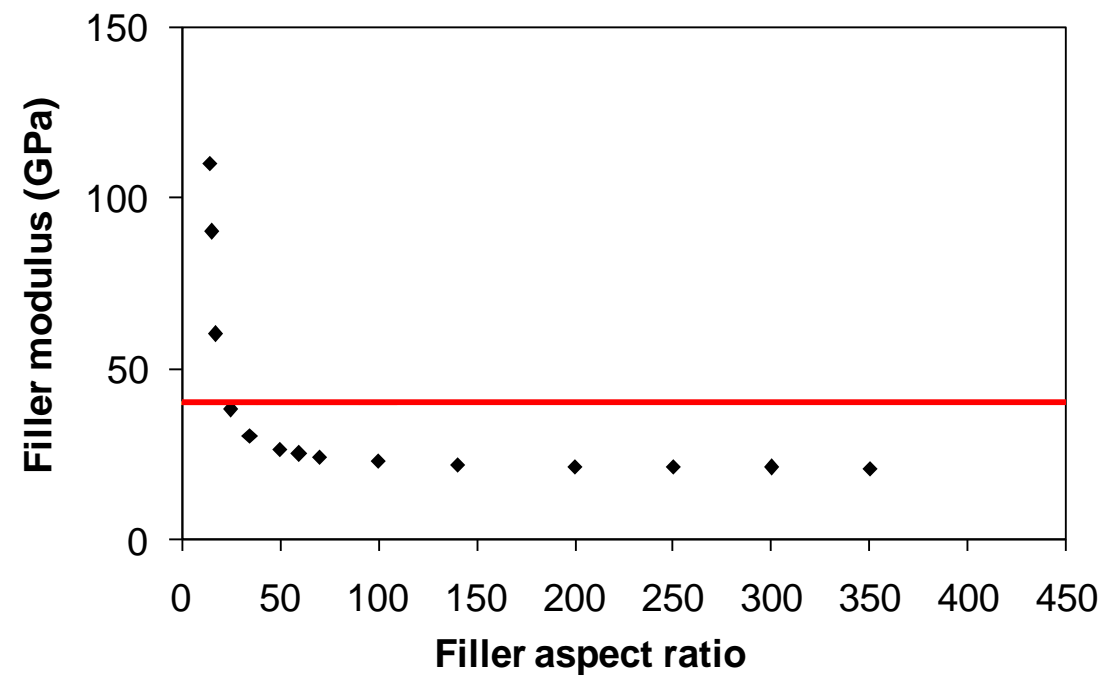

Figure 8: Non-linear inverse correlation between filler aspect ratio and modulus, obtained by fitting the H-T model to the experimental data of PA-EG. The red horizontal line denotes the threshold modulus of $40 \mathrm{GPa}$ that was assumed for GNP.
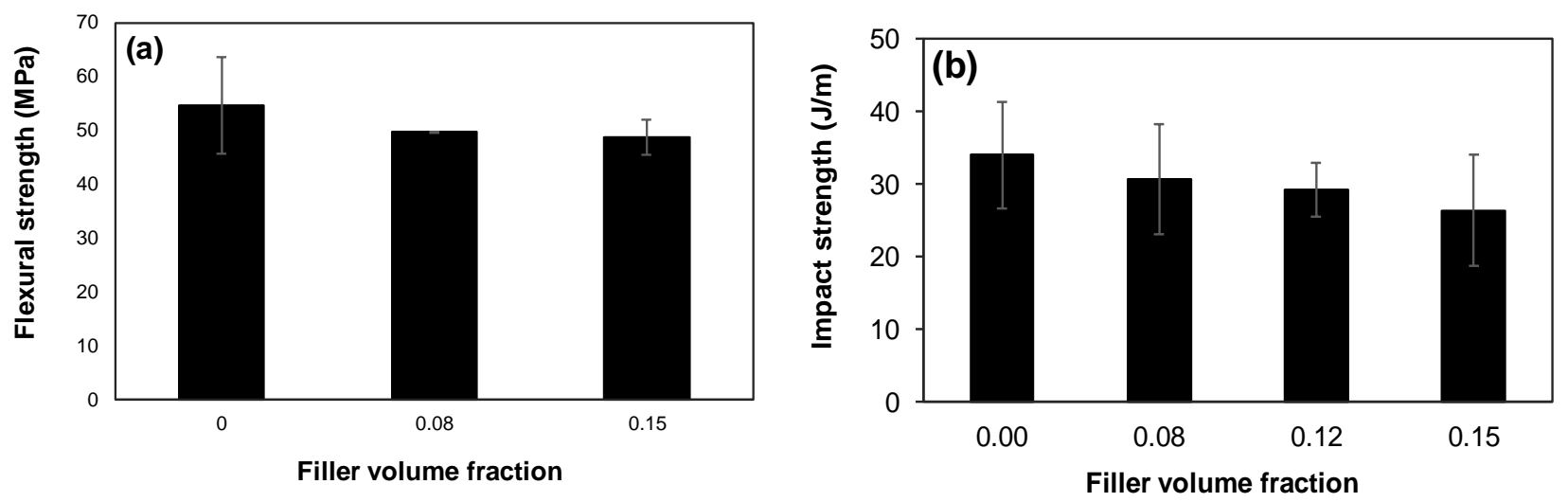

Figure 9: Flexural strength (a) and impact strength (b) of PA-EG composites at different filler volume fractions. Error bars show \pm 1 standard deviation. 

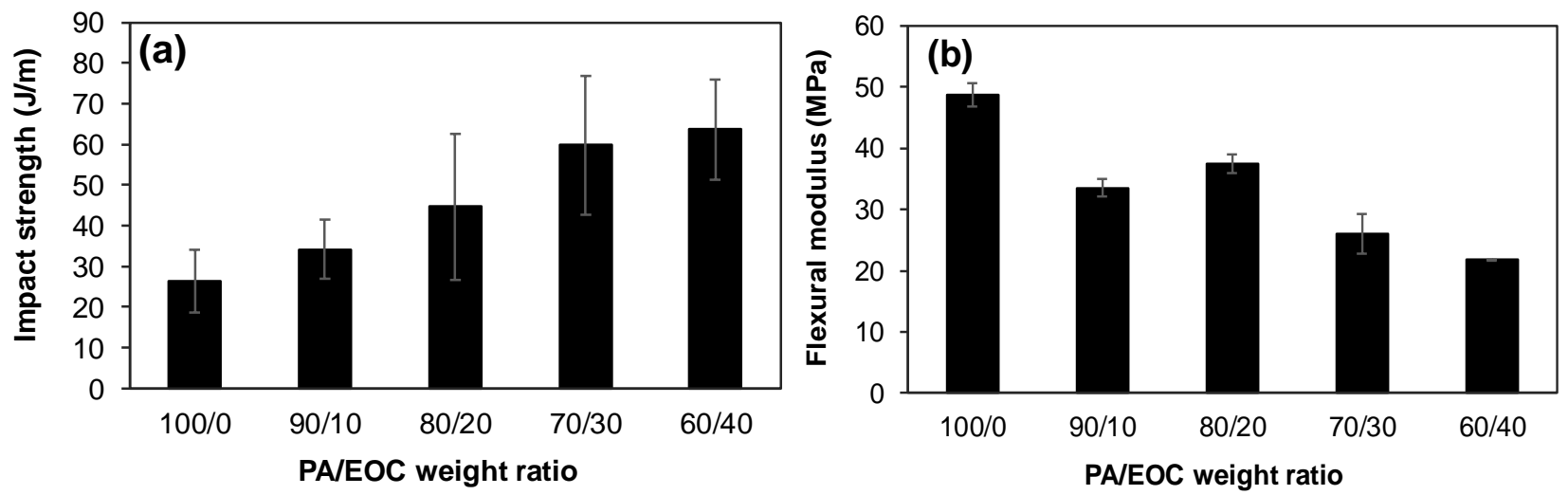

Figure 10: (a) Impact strength (b) and flexural moduli of PA-EG composites at $\Phi=15 \mathrm{vol} \%$ containing EOC at different PA/EOC weight ratios (from 100/0 to 60/40).

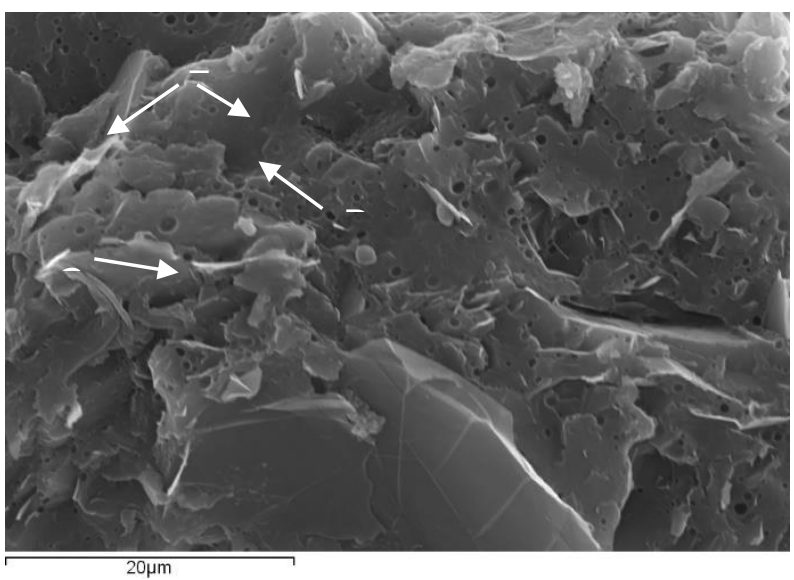

Figure 11: A fracture surface (etched in xylene) of a PA-EG composite at $\Phi=4$ vol $\%$ and containing EOC at 80:20 PA/EOC weight ratio. The EOC is dispersed as domains of $1 \mu \mathrm{m}$ in diameter. 
Table 1: XPS data of FG and EG

\begin{tabular}{ccc}
\hline Name & Position $(\mathbf{e V})$ & Atom Conc., \% \\
\hline FG & \\
\hline C 1s & 284.1 & 90.9 \\
O 1s & $530-535.1$ & 7.1 \\
\hline C 1s & EG & \\
O 1s & $284-290.5$ & 96.2 \\
\hline
\end{tabular}

Table 2: Surface energies of composite constituents

\begin{tabular}{|c|c|c|c|c|}
\hline & \multirow{2}{*}{$\begin{array}{c}\begin{array}{c}\text { Dispersive } \\
\text { component } \\
m J / m^{2}\end{array} \\
\gamma_{\mathrm{L}} \\
\end{array}$} & \multicolumn{2}{|c|}{$\begin{array}{c}\text { Acid-base interaction } \\
\text { components } \\
m J / m^{2} \\
\end{array}$} & \multirow{2}{*}{$\begin{array}{c}\begin{array}{c}\text { Total surface energy } \\
\mathrm{mJ} / \mathrm{m}^{2}\end{array} \\
\gamma_{\mathrm{T}} \\
\end{array}$} \\
\hline & & $\gamma+$ & $\gamma-$ & \\
\hline PA & 41.9 & 0.04 & 15.5 & 43.4 \\
\hline EOC & 33.9 & 0.01 & 11.6 & 34.5 \\
\hline GNP & 41.2 & 0.06 & 12.6 & 42.9 \\
\hline FG & 45.3 & 0.33 & 51.9 & 53.6 \\
\hline
\end{tabular}

